\title{
EL MARGEN DERECHO DEL ENUNCIADO
}

\author{
Catalina Fuentes RodríGuez \\ Universidad de Sevilla
}

\section{RESUMEN}

El margen derecho oracional no ha recibido la misma atención que la periferia izquierda. En él aparecen desde complementos de la enunciación o modales hasta conectores o estructuras propias. Estas se caracterizan por introducir, tras una pausa, una nueva formulación que revisa lo previo y lo reorienta, lo hace progresar temáticamente o lo comenta, desde la evaluación del hablante. Es un después informativo y enunciativo, que provoca una nueva interpretación de lo precedente.

Palabras clave: periferia oracional, sintaxis, información, formulación, dislocación.

\section{ABSTRACT}

The right periphery of the sentence has not received the same attention as the left periphery. Sentential adverbials, modals, discourse markers or clausal structures can appear in this right periphery. These are characterized by introducing, after a pause, a new formulation which revises the previous one and adds a reorientation, a thematic progression or a speaker's evaluative comment. It is an afterthought, which leads to a new interpretation of the preceding information.

Key Words: sentence periphery, syntax, information, formulation, dislocation.

RECIBIDO: $10 / 07 / 2011$

Aprobado: 10/04/2012

\section{SINTAXIS SUPRAORACIONAL Y MÁRGENES ORACIONALES}

La investigación sobre la sintaxis supraoracional se ha centrado, sobre todo, en el margen izquierdo (MI) o left periphery ${ }^{1}$ : así los trabajos referentes a marcadores discursivos, modificadores modales, tematización, dislocación, etc., estructuras todas ellas externas a la oración. Algunos corresponden a elementos con función relacionante, y otros a

\footnotetext{
${ }^{1}$ Quisiera agradecer a los dos informantes anónimos sus observaciones, que me han ayudado a mejorar la primera versión del presente trabajo. Este se ha realizado dentro del marco del Proyecto FFI 2009-10515, del Ministerio de Ciencia y Tecnología y del Proyecto de Excelencia de la Junta de Andalucía HUM 5872, ambos cofinanciados por fondos FEDER.
} 
sintagmas que no representan argumentos o adyacentes del verbo, sino que actúan como un marco informativo o argumentativo (desde un punto de vista semántico-pragmático).

Esta periferia izquierda es el lugar de los modificadores de modalidad, como lamentablemente:

(1) Lamentablemente, se han terminado los ejemplares.

Según Alarcos 1973 este adverbio puede ser parafraseable por una estructura «Es + adjetivo + que + oración»: «Es lamentable que se hayan terminado los ejemplares». Por ello lo llama atributo oracional. Su posición al inicio de la frase no es fija. Puede aparecer intercalado o al final, pero siempre formando un grupo entonativo. Kovacci 1999 lo considera un «adverbio de frase» ${ }^{2}$.

En el MI situó Gutiérrez Ordóñez 1997 una función propia, el circunstante. Corresponde generalmente a un sintagma nominal (u oración subordinada) que aparece seguido de pausa y establece un marco en el que se sitúa todo lo asertado en la oración, como la construcción subrayada en el enunciado siguiente:

(2) Hace solo unos meses, diversas agencias de prensa dieron cuenta de una pequeña rebelión y una serie de saqueos de comercios en el barrio blanco de Westwood, luego de que un grupo de personas saliera de la proyección de New Jack City, la historia de un traficante de drogas en Harlem (CREA ${ }^{3}$, Granma Internacional 12, 1996, núm. 20).

Los elementos que aparecen en esta distribución entrarían dentro de lo que Fernández 1993 y Martínez 1994 llamaron «función incidental»: una función distinta, caracterizada por su aparición marginal (entre pausas) y por introducir una predicación secundaria. El origen de este término está en el estudio de Lapesa 1975 sobre los adjetivos del tipo:

(3) Convencida, Ana se dirigió a pedirle disculpas a Susana.

Convencida introduce una predicación secundaria que afecta no solo a Ana, sino también a todo el contenido de la oración. En este caso parece aportar un contenido causal.

Hay complementos que aparecen en esta distribución y que ya no modifican lo dicho en la oración, el «contenido proposicional», sino que pertenecen al campo de la enunciación. Kovacci 1992 los llama «modificadores de modalidad». Para Dik 1989, pp. 264-265, son «extraclausal constituents».

\footnotetext{
${ }^{2}$ Cf. sobre esto Fuentes y Alcaide 1996; Fuentes Rodríguez 1987a, 1991; Quirk et al. 1972, quien los denomina disjuntos o subjuntos.

${ }^{3}$ CREA: Corpus de Referencia del Español Actual, Real Academia Española.
} 
(4) Para no mentir, el regalo nos había costado ciento cuarenta euros.

El MI también es el ámbito de la tematización (Hidalgo 2003):

(5) El dinero, hay que tenerlo a buen recaudo.

Todos estos segmentos constituyen un «antes» en la enunciación y actúan como marco informativo. Su función abarca sintácticamente todo lo dicho. Por ello, el MI es el lugar de inserción de la periferia oracional, de los contenidos que no se centran en la proposition, sino en las coordenadas macroestructurales: enunciación, modalidad, información, argumentación (Fuentes Rodríguez 2000). Configuran el enunciado y demandan para su estudio un análisis más englobador, que supere las limitaciones de la sintaxis oracional (Fuentes Rodríguez 2005a). Lo ilustramos en el esquema siguiente:

\begin{tabular}{|c|l|}
\hline Ámbito SUPRAORACIONAL & \multicolumn{1}{|c|}{ FUnCIÓN SINTÁCTICA } \\
\hline Dictum & Circunstante \\
\hline Enunciación & $\begin{array}{l}\text { Complemento enunciación } \\
\text { Complemento locutivo } \\
\text { Complemento de aserción }\end{array}$ \\
\hline Modalidad & Complemento de modalidad \\
\hline Información $n^{4}$ & Complemento temático \\
\hline
\end{tabular}

TABLA 1: Ámbito oracional y funciones sintácticas en el margen izquierdo (MI)

Este análisis debe extenderse al otro margen oracional, el derecho (MD), hasta ahora olvidado en español. En él encontramos complementos con las mismas características: están marcados por pausas, y no introducen una aportación al contenido verbal. Es decir, no siempre pertenecen al dictum ${ }^{5}$, sino a campos más externos como los citados anteriormente: la enunciación, la modalidad, la focalización, etcétera.

\footnotetext{
${ }^{4}$ En cursiva aparecen los ámbitos supraoracionales de inserción de la predicación: dictum, enunciación, modalidad o información, y en redonda la función sintáctica que desempeña el segmento que aparece en el MI correspondiente a dichos ámbitos. La base metodológica de esta división se halla en Fuentes Rodríguez 2000. Las funciones nombradas están descritas en Fuentes Rodríguez 2005a y 2007.

${ }^{5}$ Seguimos la distinción de Bally 1965 entre modalité y dictum.
} 
(6) Ha venido Susana con unos amigos franceses, afortunadamente.

(7) Van a volver a pagarnos los complementos salariales, o eso dicen.

(8) Él no aceptó reunirse con el delegado provincial, algo que a mí no me parece del todo bien.

(9) Marisa ha dejado a su marido, lo cual va a acarrearnos serios problemas.

(10) Esa carretera está siempre colapsada, sobre todo en verano.

(11) Debería comprarse el piso de Alcalá, me parece a mí.

(12) Tiene cuatro hijos, me han dicho.

(13) Es una persona muy adecuada. Tiene una buena formación, además.

(14) Esta habitación es demasiado oscura, ¿verdad?

(15) Él no es el culpable, para que te enteres.

Dik 1997a, p. 311, incluye entre los «extraclausal constituents» (ECCs) complementos del MI as for students («Theme»), they won't be invited, o el MD He's a nice chap, your brother («Tail», «Clarification»). Es hora, pues, de sistematizar sintácticamente también este después enunciativo.

\section{LA MOVILIDAD EN SINTAXIS Y LA PERIFERIA DERECHA}

El concepto de «movilidad» en sintaxis se entiende en la bibliografía científica de dos modos:

a) Como una distribución propia de algunos elementos enmarcadores del texto, en alternancia con otras posiciones. Esta distribución diferencia funciones, categorías sintácticas o incluso clases de palabras.

b) Como una distribución marcada informativamente.

El primer aspecto es el que se utiliza como criterio definidor de los marcadores discursivos, elementos externos a la oración y diferentes de las conjunciones. Estas tienen una posición fija: aparecen siempre entre las dos oraciones para establecer la conexión. Los marcadores del discurso, los disjuntos y otros adverbios pueden tener movilidad, ocupar distintas posiciones, y esto deriva en rasgo identificador de su carácter extraoracional (Greenbaum 1969; Martín Zorraquino y Portolés 1999; Fuentes Rodríguez 1996, 2001, 2009), aunque no se analiza la posibilidad de diferencias semánticas y/o comunicativas añadidas a estos cambios de posición:

(16) a. He llamado varias veces esta mañana $y$ he dejado varios mensajes en el contestador.

b. He llamado varias veces esta mañana. He dejado, además, varios mensajes en el contestador. 
La segunda interpretación introduce otra variable: la informativa, una dimensión ligada a la estructura textual. A ella pertenece el concepto de dislocación. Hablar de dislocación implica una distribución «anómala», no estándar. Se justifica en los siguientes términos:

a) De registro: coloquialidad.

b) De circunstancias comunicativas: oralidad.

c) De relevancia informativa ${ }^{6}$.

Pero ¿se trata solo de una forma de destacar informativamente un segmento, o, por el contrario, la distribución en el margen final de la oración tiene relevancia sintáctica? Para responder a esta pregunta, revisaremos las aportaciones que la bibliografía científica nos ofrece.

\subsection{Dislocación y afterthought}

La «dislocación» consiste en la colocación en posición inicial o final de frase de un constituyente sintáctico temático y dado (Francesconi $2005^{7}$ ). En la dislocación a la derecha (DD) el elemento tiene que ser conocido o fácilmente recuperable ${ }^{8}$.

Para Pérez Bello 1998, p. 209, este hecho informativo es el que diferencia la dislocación de la topicalización: «en la topicalización [el componente] es siempre remático (nuevo), en la dislocación es temático (dado) $»^{9}$. Entre las DI (dislocación a la izquierda) y las DD la diferencia es de registro. Las DI se encuentran también en los textos escritos, mientras que las DD son propias de la oralidad ${ }^{10}$. Por tanto, en este margen derecho encontraríamos un segmento propio de lo oral que introduce información dada.

${ }^{6}$ Cf. Padilla 2001, Vion 1992, Rodman 1975, Samek-Lodovici 2006, Doetjes et al. 2002, Ashby 1988, Vallduví 1994.

7 Se remonta para ello a Bally 1965 y a Galmés 1955.

${ }^{8}$ Berruto 1985, pp. 67-68, define «dado» como «solo ciò che è presente, menzionato, nel contesto precedente a non lunga distanza, ovvero è da esso derivabile mediante strette regole di semantica lessicale (sinonimizzazione, parafrasi, iper- e iponimizzazione, deissi anaforica» (apud Francesconi 202-203, en nota 1). Villalba 2011 considera algún caso en el que el elemento no es información conocida, pero reconoce que en la mayoría se trata de reactivar un tópico presente en la mente de los hablantes.

${ }^{9}$ Retoma Zamora 2002, pp. 457-463.

${ }^{10}$ Francesconi 2005 denomina también a la DIS aggancio o raccordo, y utiliza este término para la toma de turno y el control de la interacción en curso. En la DD Berruto 1985, p. 61, habla de camaraderie y ammiccamento. La DD propiamente dicha establece una relación de cooperación entre hablante e interlocutor, «una sorta di (supposta) confidencialità» (Pérez Bello 1998, p. 213). 
Sin embargo, algunos autores ya establecen distinciones dentro del MD y hablan de otros fenómenos distintos a la dislocación. Berruto, por ejemplo, diferencia ripensamento de dislocazione a destra vera e propria ${ }^{11}$. El ripensamento está siempre articulado en dos unidades tonales, con una pausa o break de entonación entre la frase y el elemento dislocado. Correspondería a la construcción:

(17) a. Ya lo ha arreglado, el coche (ripensamento).

frente a

(17) b. Ya lo ha arreglado el coche (DD).

La DD sirve para establecer una especial relación comunicativa, de tono familiar, con el interlocutor. El ripensamento, por su parte, es una especie de "glosa explicativa», o una autocorrección, que repara las ambigüedades que pueden surgir en el discurso ${ }^{12}$. De este modo, DI y DD realizan dos funciones discursivas distintas que corresponden a dos esquemas entonativos también diferentes. Y es este punto el que nos interesa especialmente, ya que introduce otra variable: una función enunciativa.

Zamora 2002 mantiene que la DD en español es poco frecuente, porque le faltaría la función pragmática de familiaridad que tiene en italiano y resultaría muy forzada ${ }^{13}$. Sin embargo, el ripensamento sí aparece en español. Así podemos verlo en Padilla 2001, p. 240: «Es una especie de descuido informativo que se pretende reparar: Yo los tengo bien $\downarrow$ los dientes». Se trata, pues, de una actividad enunciativa, reformulativa.

11 Esta última pertenece a la gramática de la frase y no tiene preeminencia entonativa. Sigue Berruto en esto a Lambrecht 1981, p. 75. Este habla de dos construcciones, tal como hemos ido explicando:

a) antitopic: «le mangio le mele», estructura que pertenecería a la gramática de la oración.

b) afterthought: «le mangio, le mele», de la que se ocuparía una gramática del discurso.

En la primera, puesto que aislamos el rema («le mangio») a la izquierda de la oración, parece más convincente interpretarlo como la dislocación del tema («le mele») a la derecha de la oración.

12 Pero, de nuevo, «el sintagma aislado a la derecha es las más de las veces temático y dado» (Francesconi 2005, p. 205). La misma postura mantiene Larsson 1979.

13 «In spagnolo la dislocazione a destra propriamente detta -la più frequente in italianoviene usata unicamente:

a) quando il costituente è veramente dato poichè è stato introdotto precedentemente e inminentemente nel discorso (¿lla tienes la cinta?) (...);

b) quando si fa riferimento a un elemento determinato e specifico-noto- (te lo tomas el café? -questo caffè-) (Zamora 2002, p. 452).

Incluso en estudios contrastivos (Villalba 2011) se muestra la escasa relevancia de la dislocación a la derecha en nuestra lengua. 
Lo mismo plantea Pérez Bello 1998, p. 257, quien introduce el concepto de afterthought (AT):

Algunas dislocaciones a la derecha son una especie de añadido al final sin el cual, sin embargo, el enunciado sería igualmente comprensible. Esta acción que se realiza en la mente del hablante se conoce con el término afterthought: el emisor se da cuenta de que el mensaje que ha lanzado puede no resultar comprensible del todo para el receptor y añade a posteriori el constituyente pleno para realizar la función de tema.

Averintseva-Klisch 2008 también habla de afterthought para los elementos de este margen derecho ${ }^{14}$ y lo caracteriza desde todos los ámbi$\operatorname{tos}^{15}$. Lo más llamativo de su propuesta es la caracterización sintáctica del mismo. Para esta autora, el AT es un segmento sintácticamente libre, algo que refrenda su independencia prosódica. Actúa como un orphan, es decir, como "a phrase that is syntactically autonomous and gets integrated into its host sentence only at the level of discourse via some discourse relation» (Averintseva-Klish 2008, p. 230). Esta relación sintáctica específica se justifica discursivamente. Concretamente, introduce un añadido:

Afterthought holds whenever the second constituent provides additional information about some discourse referent in the first constituent, in such a way that the information helps to identify this discourse referent (p. 234).

Averintseva-Klish da un paso más y considera el AT una relación discursiva subordinante en el nivel cognitivo. Es una estrategia de repercusión enunciativa o comunicativa (local repairing strategy), que se dirige hacia la oración principal, como un proceso anafórico.

(18) La he traído, la caja.

El hablante hace una pausa porque encuentra insuficiente o poco adecuada su enunciación previa y añade al final de la oración o del enunciado un constituyente que aporta una información importante. Pertenece, por tanto, al plano enunciativo, a la formulación -según Berruto a

\footnotetext{
${ }^{14}$ A diferencia de la right dislocation proper.

${ }_{15}$ Aclara que, sintácticamente, la DD permite menos inserciones entre la oración principal y dicha dislocación. Por ejemplo, no es posible insertar cláusulas subordinadas, ni adiciones opcionales de ninguna clase. La dislocación a la derecha (DD) ocupa una posición fijada en la oración principal (en la periferia derecha). La AT, por su parte, varía su posición en la oración principal. No requiere concordancia morfológica entre el sintagma nominal y el pronombre inserto en la oración, y permite varias inserciones: adiciones como I mean (quiero decir) o bien oraciones subordinadas. Semánticamente, el AT es más libre que la DD, que está más restringida. Esta solo puede referirse a un sintagma específico definido, y no son posibles ni sintagmas nominales indefinidos específicos ni cuantificados.
} 
una «gramática del discurso»- y por su naturaleza sintáctico-pragmática está emparentado con la glosa explicativa. Al mismo tiempo, está relacionado anáforicamente con la enunciación anterior. Es un añadido explicativo que rellena de material semántico el posto vuoto que, según Berruto 1986, actúa catafóricamente, remitiendo a esta segunda enunciación.

Estas propuestas, pues, caracterizan el MD como un segmento sintácticamente independiente de lo anterior, que enunciativamente aporta una función explicativa.

\subsection{Otras propuestas informativas: AT, foreground, background y reinterpretación}

Al mismo tiempo, los estudios que desde la SDRT (Segmented Discourse Representation Theory) se acercan a las oraciones subordinadas utilizan la distinción entre background y foreground, en un enfoque más discursivo (Talmy 1978, Thompson 1987, Tomlin 1987, Erlbagh 1987, Asher y Lascarides 2003, Asher y Vieu 2004, Vieu y Prévot 2004), lo que nos permite entender y situar el AT.

Esta oposición figura-fondo, o primer plano-fondo, se describe por el diferente peso que tienen las acciones en el desarrollo lineal de la narración. El foreground es el material lingüístico que se encarga del progreso de la narración en el tiempo, mientras el background (fondo) es lo durativo y descriptivo, que sirve para rodear y elaborar ese primer plano.

Para Givón 1987 estos conceptos actúan de manera dinámica en el discurso. Una proposición que es asertada (primer plano) se convierte más adelante en fondo. Esto supondría que en los enunciados con MD la oración "principal» ${ }^{16}$ se convertiría en el fondo, desde el que reinterpretar la nueva adición de un segmento.

Givón afirma que una cláusula adverbial es tópica o está presupuesta pragmáticamente solo cuando precede a la principal. Y es focus o información asertada cuando la sigue. Según este autor, la cláusula antepuesta suele aparecer en los lugares temáticos mayores y tiende a conectar o situar la unidad temática que sigue frente a la precedente. Funciona como una combinación de rasgos anafóricos y catafóricos. La pospuesta, por su parte, aparece frecuentemente en medio de las unidades temáticas, y funciona más como rasgos de «re-orientación».

Aquí tenemos la clave, y esto nos permite entender informativamente el proceso: la nueva adición enunciativa, el nuevo movimiento formulativo del hablante que introduce el MD lleva a que lo previo se convierta en el ground o fondo desde el que interpretar lo que viene. En definitiva, es un añadido posterior (AT) que lleva a una reinterpretación.

\footnotetext{
${ }^{16}$ Host en otras terminologías.
} 
La «reinterpretación» es un concepto utilizado en la bibliografía francesa en el marco de la «reformulación». Se trata de una actividad enunciativa del hablante que vuelve sobre lo anterior, en un movimiento retroactivo de relectura: «une deuxième interprétation qui part d'une première déjà effectuée, au moins en principe» (Nølke 1994, p. 60). Estaría ligado a ese ripensamento o afterthought, si este se entiende con el fin de aclarar la enunciación.

Para García Negroni 2005, la reinterpretación viene provocada por el empleo de ciertos términos de la lengua o por el encadenamiento de ciertos enunciados en el discurso. Se define como la atribución de un sentido s'1 a un enunciado, que antes tenía atribuido un sentido s1. Un enunciado puede ser el contexto de reinterpretación de otro que le precede. En el segundo segmento introducimos una información que lleva a retomar la información anterior en el contexto de las circunstancias añadidas ${ }^{17}$. Interviene en el cálculo del sentido de los enunciados en el discurso y debe, por ello, estar previsto por el sistema explicativo de una lengua. Sin embargo, la autora no desarrolla ampliamente el estudio de marcadores de esta operación enunciativa.

Todas las propuestas anteriores consideran que las estructuras sintagmáticas que aparecen en el MD muestran una operación enunciativa, en la que el hablante obliga al receptor a entender de otro modo lo dicho en el primer segmento, al añadir una nueva información. Obedece a un cambio en la formulación, al darse cuenta el hablante de que lo previo no cumple su objetivo comunicativo. A la vez, implica el desdoblamiento del emisor en dos enunciadores. En este sentido sería paralelo a la oración parentética ${ }^{18}$, aunque muestra diferencias con respecto a ellas.

\subsection{Propuesta sintáctica: el tail o coda}

En el plano sintáctico, el MD ha sido tratado en la gramática funcional bajo el concepto de tail (Dik 1997a, 1997b; Brunetti 2009). Dik utiliza este nombre para analizar constituyentes que presentan información tendente a clarificar o modificar la unidad a la que se adjuntan (Dik 1997b, p. 401). Formarían parte de los extraclausal constituents (ECC): «ECCs are not part of the clause proper, but more loosely associated with it in ways which can most adequately be described in terms of pragmatic functionality» (Dik 1997a, p. 310).

Estos elementos extraclausales tienen:

\footnotetext{
${ }^{17}$ Lo plantea en dos tipos de movimientos: una auto-reinterpretación en el discurso propio (Luc est content. Peut-être), que es la que corresponde a las estructuras que analizamos, y la heteroreinterpretación, en el diálogo, entre las intervenciones de dos hablantes.

${ }_{18}$ Cf. Fuentes Rodríguez 1998, Schneider 2007, Brinton 2008.
} 
1. Movilidad.

2. Aislamiento entonativo.

3. Marginalidad sintáctica (no afectan a la estructuración interna de la oración).

4. Desempeñan una variedad de funciones pragmáticas: «(i) the management of the interaction, (ii) comments on the content of the clause proper, and (iii) the organization of the content of the expression, in relation to the context in which it occurs» (Dik 1997a, p. 311).

El tail es «a final constituent which falls outside the clause proper» (Dik 1997a, p. 418). Aparece después de la oración, como un añadido o una inserción parentética. Ocuparía este margen derecho, y albergaría las funciones de dislocación, reformulación, o lo que estamos llamando $\mathrm{AT}^{19}$.

\subsection{El MD: caracterización sintáctico-informativa}

Los sintagmas u oraciones que aparecen en este hueco sintáctico del MD pueden ser caracterizados del siguiente modo:

1. Funcionalmente, no son complementos verbales. No pertenecen, pues, al esquema oracional. Tienen una función marginal o constituyen una nueva unidad sintáctica, un enunciado distinto.

2. Entonativamente, los precede una pausa marcada.

3. Informativamente, introducen un añadido de información que aclara, restringe, o reinterpreta lo previo. Pertenece al plano de la formulación discursiva y supondría una reinterpretación, ya que pasaríamos de entender una oración como aserción simple a reinterpretarla en relación con el segmento introducido. Lo previo se convierte en fondo al que se incorpora el añadido

19 Geluykens 1987 resume sus características así:

1. Los tails aparecen en la conversación hablada no planeada.

2. Constituyen generalmente estrategias de reparación conversacional: el hablante aclara la referencia de un pronombre indicado anteriormente.

3. La reparación está a menudo «autoiniciada».

4. Van precedidos de una pausa corta.

5. Van acompañados a menudo de una expresión metacomunicativa como I mean.

6. Los usa el hablante cuando considera que puede haber una pérdida de claridad de la referencia, ya sea porque a) el elemento pronominal en la cláusula puede ser tomado como correferencial a más de una unidad en el discurso precedente; b) cuando el referente es «inferible» (subtópico) y no explícitamente mencionado en el segmento precedente. El hablante no siempre sabe si se han establecido ya las oportunas asunciones que lo ligan a lo previo (cf. Dik 1997b, p. 403). 
provocando una nueva información que reorienta lo previo. Esto supone un segundo movimiento enunciativo o $\mathrm{AT}^{20}$.

Esta actividad enunciativa que introduce un segundo movimiento y provoca una vuelta hacia atrás en la interpretación puede manifestarse en combinatorias sintagmáticas que comparten este MD con el MI, o bien en segmentos exclusivos del MD. Véamoslas por separado.

\section{EL MD COMO UNA DISTRIBUCIÓN OPCIONAL}

En el MD podemos encontrar categorías sintácticas o combinaciones sintagmáticas que pueden alternar esta posición con el MI:

\subsection{Categorías sintácticas}

3.1.1. El MD es una de las distribuciones de ciertos elementos externos a la oración: los conectores. Es más, Greenbaum 1969 y Quirk et al. 1972 definen los conjuncts en virtud de la posibilidad de tener movilidad en la oración. Es una característica definitoria de los relacionantes supraoracionales como categoría distinta a las conjunciones, como hemos señalado más arriba (Fuentes Rodríguez 1987b, 1993, 1996, 2001, 2009; Martín Zorraquino y Portolés 1999):

(19) Nos habíamos llevado bastante tiempo pensando qué comprarle. El regalo nos había costado 140 euros, además (encima). Así que no me digas que fue solo salir del paso.

Aunque esta posición final sea admitida por los conectores, poseen algunas características propias:

1. Es necesario que el enunciado no sea excesivamente largo.

2. Aportan siempre un contenido añadido, un «después» enunciativo, que hace entender la relación de manera posterior a la información recibida.

Es decir, si emito una comunicación como:

(20) a. La fecha fue impuesta por el secretario de Comercio norteamericano, Robert Zoellick. No todo está perdido, sin embargo. Hay plazo hasta junio del 2005 para acceder al esquema de fast track norteamericano (CREA, Caretas 1819, 15/04/2004).

Primero entiendo las dos informaciones de manera aislada y posteriormente traslado al oyente el hecho de que están opuestas o anti-

\footnotetext{
${ }^{20}$ Por tanto, reinterpretación y AT no son incompatibles, sino conjugables.
} 
orientadas. Evidentemente, no es tan necesario hacerlo porque los contenidos de los enunciados ya apuntan en esta dirección. En otros casos en que de lo que se trata es de marcar la coorientación, el relacionante añade una enfatización a la misma.

(20) b. La fecha fue impuesta por el secretario de Comercio norteamericano, Robert Zoellick. No todo está perdido, además (encima).

Se subraya así el contenido de la conexión. La posición final es una posición relevante, lugar preeminente informativamente hablando.

Un caso específico es el de los marcadores o conectores que indican añadido de información nueva o colateral, es decir, los conectores de digresión o aquellos aditivos que indican información secundaria y que acompañan estructuras de comentario como por otra parte, por otro lado, por lo demás.

(21) Lo cierto es que José Bono se ha manifestado siempre, sin rubor alguno y desde el socialismo, orgullosamente patriota y profundamente español. Por lo tanto, entra en el mejor lugar para sentirse cómodo, a pesar de la trampa que puede tenderle Zapatero con su ridícula promesa de retirar a nuestros soldados de Iraq. Ridícula e inviable, por otra parte (CREA, La Razón, 24/03/2004).

3.1.2. También entran aquí otras «partículas discursivas» cuya función es establecer contacto con el receptor, o llamar su atención sobre un segmento informativo. Su función es a veces simplemente apelativa, y otras une a lo apelativo una operación de focalización informativa:

(22) Ehhhhmm... sí, metí la pata un par de veces. Pero solo dos, ¿̨eh? Una de ellas, si en vez de pinchar hubiera estado sacándome el carnet de conducir, habría sido de las gordas (CREA, Efimero 04206006. Weblog 2004)

(23) Debía ser cosa del proxy de algunos servidores (algo así como una caché pero del servidor que te proporciona internet... eh eh, hablo de oídas) pero nada: ni cambiándole el nombre tres, cuatro, cinco veces a Bisbal y sus estrellas. Ni cargándome todo el diseño y sus imágenes. Nada. Hasta que por fin, a Juan Carlos se le ocurrió la solución: «¿Por qué no pruebas a editar la página de inicio (el index.html o default.html, el que contiene el iframe) para que el proxy detecte que es una versión posterior a la de Bisbal?». ¡Premio! Parece ser que eso era. El proxy, caprichoso como él solo, pasaba del index.html anterior y se había quedado el index.html de Bisbal, el muy canalla. Pues nada, solucionado.

Uh... qué interesante, ¿iverdad? (ibidem) ${ }^{21}$.

\footnotetext{
${ }^{21}$ Estas unidades fueron estudiadas por Briz y Estellés 2010 como hedgings.
} 
A este grupo pertenecen todos los elementos que piden confirmación: ¿no?, ¿verdad?, ¿entiendes? y ejercen esa doble función. Tienen también una función de imposición sobre el otro: argumentativamente son refuerzos de su argumento, quieren implicar al receptor para que le dé la razón. En cierto modo, cuando son enunciados con fuerza articulatoria, actúan como intimidadores, ya que el oyente no puede rebatir el argumento:

(24) Pero bueno, yo creo que la tenemos más difícil, porque nos acostumbran a vivir de una manera en la que luego no te puedes. Hombre, hay más posibilidades, pero también hay más gente que aspira a esas posibilidades. Con lo cual los que las cogen son muy pocos. Sí, hay más posibilidades de estudiar. Sí. Después, ¿para qué te vale? Es que no te vale, en la práctica no te vale para nada, ¿entiendes? (CREA, Entrevista CSC003, hombre, 22 años, 1998).

3.1.3. Los adverbios de enunciación o de modalidad pueden hacer recaer su acción sobre todo lo anterior:

(25) Su pensamiento estaba un poco nublado, francamente.

(26) a. El médico ha llegado, afortunadamente.

b. El médico ha llegado, menos mal.

El hecho de que estos elementos aparezcan al final obliga al hablante a volver sobre lo anterior, sobre su propia actividad comunicativa. No es lo mismo entender como un enunciado puramente informativo ( $E l$ médico ha llegado) que entenderla como un enunciado que se emite como información valorada positivamente (cf. 26a). En (26a) el hablante informa de un hecho y añade a continuación que lo deseaba, mientras que en (25) el hablante informa de un hecho y posteriormente lo presenta como una opinión, lo que cree en realidad, siendo franco y sincero.

¿Qué diferencia existe entre colocar estos elementos en el MI o en el MD? Si aparecen al principio, el hablante hace entender al oyente desde el primer momento que la información está marcada subjetivamente. Con el añadido posterior, estamos en un AT, es decir, primero se ofrece una información objetiva y luego se provoca una ruptura y se da paso a la subjetividad.

También podríamos encontrar otros elementos ligados a la formulación:

(27) Su comportamiento no era lo más «adecuado», por así decir.

En este caso aparece un operador enunciativo, que se aplica sobre un elemento previo, cuya enunciación se comenta como imprecisa. Sería un hedge, elemento que indica que lo dicho anteriormente es fuzzy, 
aproximado $^{22}$, y atenúa el contenido del elemento emitido ${ }^{23}$. También se utiliza este término para los casos en que se mitiga la fuerza del acto de habla realizado en el enunciado.

\subsection{Sintagmas u oraciones que actúan como complementos supraoracionales}

3.2.1. Por extensión, pueden aparecer en esta posición todos aquellos segmentos que cumplen una función enunciativa o modal, por ejemplo, las oraciones adverbiales que actúan como complemento de enunciación (final o causal) (cf. 28-30) o de la aserción (cf. 31):

(28) Firmó el documento sin dudar, para que veas.

(29) Rabanales. Y en su reaparición en Marbella -cornada a Camino- cortó cuatro orejas y rabo, por si habia dudas (CREA, S. Trixac, Lances que cambiaron la Fiesta, 2001).

(30) Para mí fue un correo generoso: él le llevó a Claudia todas las cartas que yo le había escrito, día por día, porque eso hacíamos (CREA, D. A. Maradona, Yo soy el Diego, 2000).

(31) Lo firmaría, cuando todos lo dicen.

La oración introducida por cuando adopta aquí un valor causal o condicional del acto de asertar (yo afirmo que lo firmaría porque todos lo dicen), o bien de su valor veritativo (si todos lo dicen es verdad que lo firmaría). Pero en estos casos el hablante establece la fuerza de su aserción en la opción de otros, por tanto deja inferir una duda posible sobre lo dicho.

Encontraríamos también aquí los segmentos enmarcadores del discurso directo:

(32) Inexplicablemente, el oficial a cargo de su custodia les dijo al día siguiente a sus superiores que el prisionero había dejado el edificio, declaró el comunicado (CREA, El Nuevo Heraldo, 02/03/1997).

${ }^{22}$ Nosotros lo hemos llamado «aproximativo» (Fuentes Rodríguez 2008).

${ }^{23}$ En la obra New approaches to hedging (Kaltenböck et al. 2010) se hace una puesta al día de este concepto. El índice ya nos muestra la diversidad y el debate en torno al término. En la introducción los editores plantean el hedging como una estrategia discursiva que reduce la fuerza o verdad de un enunciado y el riesgo que corre el hablante cuando enuncia una aserción fuerte (atenuación o mitigación). Este concepto se caracteriza por su multifuncionalidad: abarca aproximativos, shields como I think, "placeholder» como thing, partículas atenuativas, etc., Fraser 2010, p. 15, define hedging como «a rethorical strategy that attenuates either the full semantic value of a particular expression, as in He's sort of nice, or the full force of a speech act, as in I must ask you to stop doing that». Algunas de las estructuras que aparecen en este MD pertenecerían a ella, concretamente los modales o los elementos que matizan la enunciación, atenuando el compromiso del hablante con lo dicho o presentando la referencia de forma vaga. Cf., asimismo, Fraser 1975; Lakoff 1972; Prince et al. 1982; Caffi 1999, 2007. 
Emitimos al principio una aserción, en la que el hablante parece asegurar la verdad de lo dicho y en un segundo momento se comunica la actitud de reserva, duda o refuerzo de la aserción:

(33) Por cuatro o cinco tías salidas -ni por 40- que estén dale que te pego no se podría establecer un principio definidor de esa naturaleza, menos aún ponerlo por escrito y divulgarlo urbi et orbe. Pero la señora Hite lo hace así, lo firma, lo rubrica con su foto en la cabeza del artículo... ¡Y lo cobra!, insisto. No sé si se percatan ustedes de la importancia que tiene este hecho (CREA, B. Ameztoy, Escuela de mujeres, 2001).

Es un «después enunciativo» que nos hace volver sobre lo previo y reinterpretarlo. El resultado es un doble enunciado, un doble contenido. Se juega con las inferencias del oyente y se focaliza la modalidad. La única limitación es la extensión, pues estos complementos modales o enunciativos no suelen ser muy extensos. De lo contrario, se perdería la idea que quiere transmitir el hablante. el MD:

La aposición es otro elemento explicativo que puede aparecer en

(34) Hace solo unos meses, diversas agencias de prensa dieron cuenta de una pequeña rebelión y una serie de saqueos de comercios en el barrio blanco de Westwood, luego de que un grupo de personas saliera de la proyección de New Jack City, la historia de un traficante de drogas en Harlem (CREA, Granma Internacional 20, 12/1996).

Podemos también encontrar oraciones de relativo explicativas y ese añadido es la clave de su valor formulativo y lo que lo diferencia de la relativa especificativa:

(35) Pero más allá de este detalle llama la atención la forma en que Velázquez realizó el retrato, en el que capta la psicología del personaje (CREA, M. A. Zalama, La pintura en España, de Velázquez a Dalí, 2002) ${ }^{24}$.

3.2.2. Aparte, debemos añadir que en esta posición se incluyen algunas estructuras, entre ellas las comment clauses (Brinton 2008; Schelfhout et al. 2004; Stenström 1995), que suelen tratarse como equivalentes de oraciones parentéticas (Ziv 2002; Dehé y Kavalová 2007; Schneider 2007). Estas se intercalan o se incluyen al final para marcar la fuerza ilocutiva de lo dicho, o indicar la fuente de información. Así son muy estudiadas I think (Brinton 2008; Kaltenbock y otros 2010), you know (Östman 1981), I suppose, I guess (Brinton 2008), I believe (Ziv 2002)...

\footnotetext{
${ }^{24}$ Para Depraetere 1996, las relativas no restrictivas pueden interpretarse de forma separada, son más asertivas que las restrictivas y actúan como un contraejemplo a la norma que establece que el primer plano informativo corresponde a la oración principal.
} 
Algunas de estas combinatorias se encuentran ya cercanas a la lexicalización. Schneider los llama reduced parenthetical clauses (RPC): estructuras no ligadas a la principal sintácticamente, que se insertan en la oración o aparecen al final en la misma posición que los adverbios de frase y establecen indicaciones pragmáticas sobre lo dicho:

(36) a. Lo firmaría, digo yo.

b. Lo firmaría, creo yo.

(37) Llegó muy tarde, me parece.

Estas oraciones de comentario son estructuras parentéticas que vienen a establecer las coordenadas enunciativo-modales de lo anterior y están limitadas a ciertos verbos.

3.2.3. Por último, y como hemos ido viendo, puede colocarse en este MD cualquier segmento sintáctico de la oración que sirva para aclarar lo previo. Es el caso de la DD:

(38) Ellos ya habían tomado la decisión, padre e hijo.

\begin{tabular}{|l|l|}
\hline $\begin{array}{c}\text { ÁmBITO } \\
\text { SUPRAORACIONAL }\end{array}$ & \multicolumn{1}{c|}{ CATEGORÍAS O ESTRUCtURAS SINTÁCTICAS } \\
\hline \multirow{2}{*}{ Enunciación } & Adverbio de enunciación \\
\cline { 2 - 2 } & Oración o sintagma complemento de enunciación \\
\hline \multirow{2}{*}{ Modalidad } & Adverbio de modalidad \\
\cline { 2 - 2 } & Oración o sintagma complemento de modalidad \\
\hline Información & Complemento temático (DI) o complemento remático (DD) \\
\hline Cohesión & Conectores \\
\hline
\end{tabular}

TABLA 2: Ámbito supraoracional y categorías o estructuras sintácticas de MI y MD

La diferencia entre MI y MD es que el MI enmarca, sitúa, y el MD reinterpreta, añade una información. Es un movimiento retroactivo que exige volver sobre lo previo y procesarlo de nuevo, ahora con los elementos añadidos.

\section{FunCIONES EsPeCíficAS DEL MD}

En el MD aparecen otras combinaciones sintagmáticas que desempeñan las siguientes funciones discursivas específicas: 
1. Restricción;

2. Progresión temática (addenda);

3. Comentario.

Se presentan de nuevo como un afterthought y se expresan a través de estructuras sintácticas cuya descripción no ha sido abordada detenidamente. Analicémoslas por separado.

\subsection{Restricción}

La reinterpretación es una operación enunciativa, que afecta también al dictum. El hablante emite un mensaje expresado en una oración, y a esta aserción general añade en un segundo momento una circunstancia. Esto restringe la extensión de lo dicho y obliga al oyente a retomarlo e interpretarlo ahora de manera más limitada ${ }^{25}$.

El resultado es el de una doble enunciación: una aserción general, a la que se suma otra restringida a un ámbito. En esta función el complemento suele ir acompañado de algún operador argumentativo como al menos, por lo menos o un operador de preferencia como en especial, particularmente, sobre todo, especialmente... (Fuentes Rodríguez 2005b).

(39) EE UU tiene, además, evidentes problemas de refinado y cualquier unidad de producción que se viene abajo se traduce en una fuente de preocupación, sobre todo con la temporada de vacaciones llamando a la puerta (CREA, El Pais, 01/04/2004).

En el fragmento anterior el oyente interpreta primero que una unidad que se viene abajo es una fuente de preocupación, y luego restringe esto a una época concreta: esto ocurre en la pretemporada de vacaciones. Esta circunstancia actúa como un «modificador realizante» $(M R)^{26}$, es decir, proporciona más fuerza e intensifica la gravedad de la preocupación.

Es necesaria la presencia de una pausa entre el enunciado general y el complemento de restricción, pausa que en el texto escrito suele ir marcada por una coma. En algún caso es más larga y puede representarse con puntos suspensivos:

\footnotetext{
${ }_{25}$ Así lo describimos en Fuentes Rodríguez 2006, p. 310: «La reinterpretación es un movimiento enunciativo cercano a la reformulación en el que el hablante vuelve sobre lo dicho y añade un segmento que establece una restricción. El resultado es una doble aserción: la del enunciado general y la de este mismo restringido en su aplicación. A diferencia de la reformulación, no anula lo anterior, sino que lo matiza. Pero, como ella, supone una intervención de control del hablante sobre su mensaje. Y una doble intención en la enunciación. Une, pues, aspectos enunciativos a la restricción propia de lo adversativo".

${ }^{26}$ Según Ducrot 1995 el modificador realizante es un elemento que intensifica la fuerza de una argumentación (Cf. Fuentes y Alcaide 2002).
} 
(40) La revista que prohibirían desde la Moncloa... si pudieran (CREA, Libertad, Boletín Informativo del Movimiento Social Republicano 12, septiembre 2005).

La interpretación que realiza el hablante de este fragmento se produce en dos fases. En la primera interpreta el primer segmento: prohibirían la revista, lo que le llevaría a la conclusión puede ocurrir que la prohiban. En un segundo momento añade lo harían si pudieran, lo que le lleva a inferir que no pueden, y a la conclusión final: no la van a prohibir. Sería equivalente a una contraposición: la prohibirían pero no lo van a hacer porque no pueden.

Especialmente, particularmente, en especial, etc., concretan la información general que aparece en el primer segmento, limitándolo a un ámbito:

(41) Florece durante el verano y en climas templados hasta el otoño, época en la que pueden verse sus flores abiertas durante el día, especialmente cuando está nublado. Resiste bien la salinidad del aire y los vientos por lo que se da en zonas de influencia marina (CREA, «Vivienda y Decoración», Revista de El Mercurio 17/7/2004).

Al menos introduce una salvedad, una reducción a un aspecto con el que el hablante se conforma. Es una limitación, pero aceptada y considerada suficiente por él.

(42) Grupos de corte cristiano y ultraconservador como la Southern Baptist Convention o la Focus on the Family presionan desde hace meses a través de sus contactos en la Casa Blanca para que efectivamente la enmienda tome forma pero según varios analistas, parece poco probable que Bush la vaya a abrazar, al menos de momento (CREA, La Voz de Galicia, 15/01/2004).

La reinterpretación constituye una operación polifónica. El hablante se desdobla en dos enunciadores: el primero emite una información y el segundo la reduce posteriormente a un campo, limita su extensión porque ve que no había sido del todo exacto. Otras veces quiere ofrecer dos informaciones, crear expectativas que luego elimina, con lo cual el enunciado es informativamente más rico. Lleva a una serie de inferencias que luego se orientan en otra dirección. En este sentido el proceso de reinterpretación no solo tiene trascendencia en el plano informativo, sino también en el argumentativo, lo que puede llevar a conclusiones diferentes a las provocadas por el primer segmento, como acabamos de ver. Actuaría, así, como un inversor o un atenuador argumentativo. Es lo que ocurre cuando se combina con eso sí, marcador de esta reorientación argumentativa (Fuentes Rodríguez 2006, 2009):

(43) Lo hizo Pinilla, cedido por el Chievo Verona, con un perfecto testarazo, eso sí, sin oposición alguna de la zaga (CREA, El Diario Vasco, 23/01/2004). 
(44) En ella se trataba de construir paso a paso toda una ciudad (de estructura muy estadounidense, eso sí, con mucha autopista y el inevitable estadio de béisbol), y gestionarla como alcalde eficaz y amante de los beneficios (CREA, «El País de las Tentaciones», El País, 30/05/2003).

El hablante puede usarlo para adelantarse a una posible objeción del oyente, o para anular las inferencias negativas que pudieran deducirse de lo anterior.

(45) -Tiene pinta de pasar olímpicamente de la crítica...

-Básicamente, le doy la importancia que tiene, la opinión de un solo individuo (muchas veces altamente cualificado, eso sí) (CREA, 20 minutos, Sevilla, 19/01/2004).

Las características de esta reinterpretación restrictiva son:

1. Posición pospuesta tras pausa.

2. Restricción.

3. Desdoblamiento del hablante en dos enunciadores.

4. Enfatización informativa.

5. Reorientación argumentativa, ya sea como realizante (intensificador) o como atenuador o inversor argumentativo.

\subsection{Progresión temática (addenda)}

El MD es utilizado a veces por el hablante para añadir otra información. Esta se presenta como algo aparentemente no planeado o que rompe la línea argumentativa o informativa de lo precedente, como una digresión a veces, pero que enriquece, reorienta o matiza la información previa.

(46) Luis se está construyendo una mansión... para Marta.

Aportamos datos que no restringen lo dicho sino que provocan otra interpretación en la que se añaden más informaciones. El contenido es diferente, pero sintácticamente, ¿cómo se manifiesta?

Aquí aparecen con frecuencia oraciones de relativo o copulativas con y. Analicemos cada caso, porque presentan características sintácticas peculiares.

En el caso de la relativa, podemos encontrar dos construcciones:

a) un tipo de explicativa.

b) una oración de relativo con antecedente oracional.

La explicativa (a), separada de su antecedente por una pausa, actúa como MD cuando presenta ese nuevo aporte de contenido como aña- 
dido marginal, no planeado, en una nueva línea enunciativa, como un AT. El hablante utiliza como marcas conectores digresivos (por cierto) o cercanos a ellos (por otra parte, por lo demás, conectores que introducen un comentario). La estructura resultante se acerca mucho a los parentéticos ${ }^{27}$.

(47) Tras este paréntesis necesario, entremos de lleno en el Primer Festival de Música Popular Cubana, suceso que por su trascendencia debe describirse en sus aspectos más significativos, que por otra parte no son pocos (CREA, El caimán barbudo. La revista cultural de la juventud cubana 324, 02/11/2004)

(48) Mi simpatía por el truhán luchaba con la aversión que me producían las revelaciones de Valeria, quien, por otra parte, hasta entonces no habia aportado pruebas (CREA, M. Torres, Hombres de lluvia, Barcelona, Planeta, 2004)

Podemos ver que esa función formulativa viene claramente marcada por la pausa y el conector (por cierto, por otra parte).

La oración de relativo explicativa añade una información que se presenta como una digresión (por cierto), es decir, una información que no estaba en el plan originario del texto en principio o se presenta como tal:

(49) Rajoy: Quisiera comenzar, para dejar claro alguna cosa, que en la primera pregunta que hice en el Parlamento hablé del IVA, la financiación autonómica, los cien euros, del cálculo de las pensiones... ¿Esto es fútbol para usted, no? Es la muestra de que no le dice la verdad a los españoles e incluso con un papel delante, como no se lo ha dicho en el caso de la resolución de Irak. Usted ha hablado ahora, entre otras cosas, del Ministerio de Fomento, lo cual resulta verdaderamente sorprendente porque nunca en la historia había sido reprobado su responsable en el Senado y había sido reprobado su responsable en el Parlamento de Cataluña, donde por cierto, usted gobierna, claro (Debate Zapatero/Rajoy, 04/03/2008).

Se trata de una información marginal que hace que tome otro matiz lo dicho anteriormente. El hablante, Rajoy, habla de los problemas que tiene en Cataluña el PSOE. A continuación añade al enunciado un segmento que lleva a la conclusión: «no debería usted tener problemas, porque tiene el poder». Esto hace que lo anterior se matice: «esto es muy grave».

El segundo caso (b) es el de las oraciones de relativo con antecedente oracional. Aquí ya no podemos sostener que estemos ante una subordinada adjetiva. Dice la Nueva Gramática de la lengua española (RAE):

\footnotetext{
${ }_{27}$ Podría aparecer también intercalado en un enunciado, pero entonces actuaría como enunciado parentético.
} 
«La posibilidad de que las relativas explicativas tengan antecedente oracional se deduce del hecho de que las oraciones puedan funcionar argumentalmente dentro de otra predicación» (p. 3326). "Así pues, el contenido de la oración antecedente es recogido de forma pronominal por el relativo» (ibidem).

(50) Sea como fuere, para España lo más urgente es el abandono de la política de los complejos. Esta puede ser la decisión más importante tomada en España por un gobierno desde 1977, lo que explica los riesgos electorales que el partido de la mayoría está dispuesto a afrontar (CREA, La Razón, 09/04/2003)

(51) - ¿Mandaste a Gastón a paseo?

-Estaba a punto de hacerlo cuando surgió Michel Bertrand y lo dejé todo por él. Nunca me lo perdonó. Fue entonces cuando tachó mi nombre y escribió la cruz en la agenda, con muy mala leche, según me contó Eloïse. Él aborrecía a Michel, que había escrito años atrás un artículo, precisamente sobre las soirées de la cava. Una pieza feroz. Se titulaba «El parásito occidental». Michel no señaló directamente a Gastón, lo cual, en opinión de este, aumentaba el agravio. ¡Ni siquiera pudo ver su nombre en Le Monde! (CREA, M. Torres, Hombres de lluvia, Barcelona, Planeta, 2004)

La función del relativo se va diluyendo y parece quedarse con el mero valor de conector, con la función de introducir una nueva información.

La Nueva Gramática de la RAE, en ejemplos como: «Pregúntele al renegado lo que con ella había pasado, el cual me lo contó» (p. 3362), habla de «relativas construidas en yuxtaposición paratáctica». Aquí el cual puede ser sustituido por quien o que, pero también por el demostrativo este, lo que «muestra la mayor independencia sintáctica de esta clase de relativas respecto de la oración que contiene el antecedente». Esto ocurre fundamentalmente con el relativo el cual y sus variantes $(\text { ibidem })^{28}$. La oración de relativo puede introducir una consecuencia del hecho expresado en la oración anterior.

(52) Si algo quedó claro al concluir la $38^{\mathrm{a}}$ Asamblea Anual de la Federación Latinoamericana de Bancos, celebrada la semana pasada en nuestro país, es que en Guatemala no hay futuro para la banca pública, lo que podría ser una mala noticia para la pequeña y mediana empresa (PYMES) (CREA, Siglo XXI, 29/11/2004)

(53) La monja tenía una edad que para la época había superado con creces la esperanza de vida, no obstante se disponía a embarcar rumbo a las islas Filipinas, lo que suponía dar media vuelta al mundo para llegar a su destino (CREA, M. A. Zalama, La pintura en España: de Velázquez a Dalí, 2002)

\footnotetext{
${ }^{28}$ Podría relacionarse con el orphan sintáctico o tail.
} 
El mismo problema sintáctico nos presenta la estructura sintáctica con $y$. Esta es tradicionalmente considerada como copulativa, que añade una información y relaciona elementos al mismo nivel. Por tanto, en

(54) Cambió hasta su voz, aprendió a escribir con la mano izquierda y alteró sus andares. Para mí, Nicole me resultó sorprendente porque estuvo cada segundo del rodaje emocionalmente implicada y... a mi servicio. Sin fisuras ni restricciones. Increíblemente vulnerable. Pero creo que ella es así en realidad (CREA, El Cultural, 17/02/2003).

¿Qué elementos une $y$ ? ¿Dos atributos? La pausa marca ya una nueva enunciación. Podríamos atrevernos a decir que y no une sintagmas, sino que se sitúa en el plano de la enunciación, de la formulación, en un nivel sintácticamente más elevado, que sobrepasa la oración y llega al enunciado, al discurso.

Ahora bien, si admitimos el MD como un hueco sintáctico, de forma paralela a como hacemos con circunstantes y complementos de la enunciación en el MI, podríamos decir que con que o y el hablante introduce un nuevo enunciado. La pausa revela de forma clara ese doble movimiento enunciativo. Veámoslo en el siguiente ejemplo:

(55) Michel no señaló directamente a Gastón, lo cual, en opinión de este, aumentaba el agravio. ¡Ni siquiera pudo ver su nombre en Le Monde! Nunca se lo perdonó. Le odiaba, y me odió a mí también cuando me vio a su lado (CREA, M. Torres, Hombres de lluvia, Barcelona, Planeta, 2004).

La pausa no es necesaria sintácticamente. Su aparición indica que no unimos dos hechos, sino dos actos de habla, dos enunciaciones. La ruptura de la linealidad que marca la pausa lleva la relación al nivel discursivo, a la relación de enunciados y supera lo oracional.

El añadido informativo puede expresarse por medio de sintagmas nominales que aportan un nuevo argumento:

(56) La penetrante mirada, la fuerza con la que aprieta la mandíbula y especialmente la manera de coger el crucifijo denotan una fuerza extraordinaria, fuerza que le llevó a cumplir su arriesgada misión (CREA, M. A. Zalama: La pintura en España: de Velázquez a Dalí, Actas, 2002).

Esta estructura explicativa que retoma el sustantivo para añadir un dato es una estrategia de progresión temática. La Nueva Gramática lo explica como una aposición. El antecedente del relativo es un sustantivo que recoge lo anterior: «Las relativas poseen, por tanto, un antecedente atributivo, lo que da lugar al doble vínculo sintáctico que caracteriza esta construcción enfática: el relativo toma ese sustantivo como antecedente y este, a su vez, entra en una relación predicativa con la oración anterior» (p. 3346). 
El añadido informativo puede ir apoyado por el conector por lo demás, para indicar esa información colateral o añadida:

(57) Está por ver si un orden internacional sano puede basarse en los principios que ahora inspiran la II Guerra del Golfo, ¿̨herencia de la gran guerra por lo demás? (CREA, La Razón, 09/04/2003).

Podemos encontrar en esta posición sintagmas adjetivos, que actúan, como las relativas explicativas, añadiendo datos colaterales o que se presentan como tales, aunque sean de gran relevancia informativa, por lo menos desde el punto de vista del hablante. En este caso de nuevo aparecen apoyados con un conector: por lo demás.

(58) Pero su observación más original es la de recomendar vinos de entre $\$ 8.000$ y $\$ 15.000$ (precios de restaurante), como ideales para las mejores alianzas con una buena comida, dejando para la satisfacción de disfrutarlos solos, quizás después de comer, los grandes vinos como un Clos Apalta o un Montes M, por lo demás nada fáciles de encontrar (CREA, Por fin viernes. Suplemento de La Segunda, 12/03/2004, Chile).

\subsection{Comentario}

Con una estructura semejante aparecen las expresiones que introducen un comentario o valoración que realiza el hablante sobre lo previo. Las oraciones más frecuentes son, otra vez, relativas de antecedente oracional o copulativas. El nuevo movimiento enunciativo viene marcado por la pausa, pero en lugar de hacer progresar temáticamente el texto o introducir argumentos, va señalando comentarios, intervenciones evaluativas del hablante, quien de este modo se desdobla en dos enunciadores. Su función, la de comentario, puede definirse, como hicimos en Fuentes Rodríguez 2012a, como «una relación sintáctico-pragmática diferente: dos oraciones, relacionadas sin presencia de nexo, con una ruptura entonativa originada por la presencia de la pausa. El segundo miembro añade una evaluación del hablante o emisión de la opinión del hablante sobre el contenido proposicional de la oración anterior». Este se convierte en tópico de la información que sigue y supone una ruptura de la linealidad sintáctica y entonativa. Podemos encontrar segmentos de comentario explícitos:

(59) Esto sucedió en Valladolid hace unas cuantas semanas. Días después invitaron a sustentar, a los maestros que no lo habían presentado, el mismo examen. Lo cual, evidentemente, es otra anomalía. (...) Según se dice, se hace a propósito para calar el aguante del maestro y la solidaridad entre el gremio (CREA, Diario de Yucatán, 04/07/1996). 
(60) Reitero que el Gobierno mantiene una disposición permanente para dialogar y debatir el tema del Mercosur con el Senado, lo cual nos parece indispensable (CREA, Sesión 42, en miércoles 20 de marzo de 1996, Chile).

(61) En consecuencia, sin perjuicio de su posible aprobación, deseo dejar constancia de mi opinión contraria a la defectuosa redacción de estas normas, lo cual, en mi opinión, en nada contribuye a beneficiar a los consumidores, por el contrario, es un elemento muy perjudicial en nuestra legislación (CREA, Sesión 38, en jueves 7 de marzo de 1996, Chile).

También encontramos segmentos que evalúan a través del decir: que ya es decir, que no es decir poco, que es mucho decir, que se dice pronto, que hemos llamado operadores de comentario (cf. Fuentes Rodríguez 2012b). Se valen de relativas como lo cual o lo que, o que, para introducir una evaluación o comentario del hablante.

(62) Sciandri es un ciclista que le ha dado categoría a su grupo deportivo. En 1993 fue el noveno corredor del mundo, según la clasificación de la UCI, lo que es mucho decir. En la actualidad, los puntos de la UCI son muy preciados por los equipos y muchos corredores se basan en ellos para ultimar sus contratos y sacar mayor provecho (CREA, $E l$ Mundo, 07/06/1994).

Las dos oraciones están ligadas a lo precedente por la referencia anafórica, pero no hay una dependencia sintáctica con respecto al verbo de la principal. Esto nos plantea ciertos problemas a la hora de explicar la relación sintáctica entre ambos segmentos. Cuando aparece un complemento, parece haber una conexión más laxa y unir dos movimientos enunciativos, y no dos segmentos de la misma oración. En el caso de la relativa, deja de funcionar como una subordinada adjetiva. El pronombre relativo actúa como anafórico. ¿Introduce una subordinación a toda la oración? ¿En qué nivel? Esto resulta más difícil de explicar. Parece razonable pensar en una relación paratáctica entre dos oraciones, en la que la cohesión viene establecida por la correferencia entre el contenido del primer segmento y el pronombre relativo que introduce el segundo. Alternativamente se podría considerar que más que parataxis estamos ante una función nueva, periférica, como las del MI.

También pueden aparecer comentarios introducidos por una conjunción coordinante (63) o con una disyuntiva (64-65), que introduce una reserva argumentativa (Fuentes y Alcaide 2002), un segmento que anula la relevancia de lo anterior.

(63) No me suena de nada, y eso es lo peor que se puede decir de un músico (CREA, C. Ruiz Zafón, La sombra del viento, 2003). 
(64) Tenerife campeón, o eso parece. La revista FHM incluye en su número especial de verano un cuadernillo curiosón (en la foto) (CREA, $R a$ dikal. Suplemento de La Opinión de Tenerife, 29/07/2004)

(65) O, si se prefiere, tantas como disciplinas hayan sido capaces de generar un método específico de conocimiento (o a la inversa, pues es el método lo que crea su objeto); de esta manera se podrá hablar como teólogo, como filósofo natural, como físico o médico, como filólogo, como jurista... y en cada caso se dirá una cosa diferente: todas esas ciencias pueden señalar hechos y formular teorías verdaderas (caso de que lo sean), pero no habrá manera de unificarlas en un conjunto o perspectiva que las comprenda a todas; lo cual tiene la ventaja adicional de que pueden convivir sin contradecirse, o eso parece (D. Yndurain, Del clasicismo al 98, 2000)

Esta segunda oración añade una circunstancia enunciativa que lleva a reinterpretar lo dicho en la primera, suspende lo anterior y cambia su orientación argumentativa.

En suma, el siguiente esquema recoge las funciones específicas de este MD y sus manifestaciones sintácticas.

\begin{tabular}{|c|c|}
\hline ÁMBITO SEMÁNTICO-PRAGMÁTICO & ÁmBITO SINTÁCTICO \\
\hline Reinterpretación restrictiva & $\begin{array}{l}\text { Complemento de reinterpretación restrictiva: } \\
\text { +operadores argumentativos (al menos...), } \\
\text { operadores de preferencia (especialmente...), } \\
\text { de reinterpretación (eso sí) }\end{array}$ \\
\hline Progresión temática (addenda) & $\begin{array}{l}\text { Yuxtaposición y/o coordinación de oraciones } \\
\text { y enunciados: relativas explicativas, } \\
\text { relativas de antecedente oracional, } \\
\text { oraciones con y (+ conector de digresión } \\
\text { o aditivo como por otra parte, por lo demás) }\end{array}$ \\
\hline Comentario & $\begin{array}{l}\text { Oración o enunciado de comentario: relativas } \\
\text { de antecedente oracional, oraciones con } y, o\end{array}$ \\
\hline
\end{tabular}

TABLA 3: Funciones del MD y sus manifestaciones sintácticas

\section{Conclusiones}

El MD constituye un hueco sintáctico en el que aparecen unidades y combinatorias que se mueven en los diferentes niveles supraoracionales, unas en distribución alternante con el MI y otras específicas: 


\begin{tabular}{|c|l|l|}
\hline $\begin{array}{c}\text { ÁMBITO } \\
\text { SUPRAORACIONAL }\end{array}$ & \multicolumn{1}{|c|}{ MI: Enmarcador } & \multicolumn{1}{|c|}{ MD: Reinterpretación, AT } \\
\hline Dictum & Circunstante & $\begin{array}{l}\text { Complemento } \\
\text { de reinterpretación restrictiva }\end{array}$ \\
\hline Enunciación & $\begin{array}{l}\text { Complemento de enunciación } \\
\text { Complemento locutivo } \\
\text { Complemento de aserción }\end{array}$ & $\begin{array}{l}\text { Complemento de enunciación } \\
\text { Complemento locutivo } \\
\text { Complemento de aserción }\end{array}$ \\
\hline Modalidad & Complemento de modalidad & $\begin{array}{l}\text { Complemento de modalidad } \\
\text { Comentario modal }\end{array}$ \\
\hline Información & Complemento temático & $\begin{array}{l}\text { Oración o enunciado } \\
\text { de progresión temática }\end{array}$ \\
\hline Cohesión & $\begin{array}{l}\text { Conectores, a excepción } \\
\text { de los apelativos e interactivos }\end{array}$ & Conectores \\
\hline
\end{tabular}

TABLA 4: Ámbito y funciones en el MI y MD

La conexión comparte ambas posiciones, pero encontramos una especialización entre ellos: casi todos los conectores (o marcadores discursivos) pueden aparecer antepuestos o pospuestos, pero hay algunos que tienen como función predominante la pospuesta. Son los apelativos o elementos interactivos $i$ no?, iverdad?, ieh?, ime entiendes?

En el plano fónico, el MD viene marcado por la presencia de una pausa que lo separa del resto del enunciado. Sintácticamente, es un segmento autónomo, que no depende del verbo de la oración. Puede corresponder a un complemento de enunciación o modal, pero también hay otras estructuras propias.

Lo específico de este MD es que supone un después enunciativo, un movimiento que hemos definido como AT. Esto implica, enunciativa e informativamente, una reinterpretación de lo anterior. Esta reinterpretación puede consistir, en el caso de las funciones específicas, en:

1. Una restricción.

2. Una progresión temática ( addenda).

3. Un comentario.

El hablante, con estas «extensiones» en el margen derecho, altera la primera interpretación, la que el oyente tenía hasta ese momento, la matiza y la comenta. Hay una intervención muy clara del enunciador, un desdoblamiento enriquecedor.

En este MD aparecen indicaciones de todos los ámbitos de la macroestructura, que de esta manera establecen, en un segundo movimiento 
enunciativo, las coordenadas con las que interpretar lo previo. Es una zona muy activa del enunciado.

Sintácticamente, estas funciones discursivas se visualizan a través de oraciones de relativo, copulativas, disyuntivas o sintagmas adyacentes que comentan todo lo previo, y que actúan en el nivel del enunciado, en un plano más global, con una relación más laxa. No hablaríamos ya de coordinación de oraciones o sintagmas (en el caso de $y, o$ ), sino de coordinación de enunciados. Los relativos no introducen un adyacente adjetivo, sino que son anafóricos que conectan enunciados en relación paratáctica.

Discursivamente, hemos podido identificar no solo la constante, el AT, como el «después», el añadido o la actividad enunciativa, sino también las funciones que cumplen: la reorientación argumentativa, la restricción o contraargumentación, la progresión temática o el comentario evaluativo. Estas funciones hasta ahora estaban limitadas a otros ámbitos sintácticos y a otros medios de expresión como los conectores o los marcadores del discurso.

Necesitamos, pues, extender la sintaxis discursiva a este MD y hablar de hueco sintáctico perfectamente definido por sus características entonativas, de distribución, sintácticas y discursivas.

\begin{tabular}{|c|c|}
\hline Áмвіто & RASGOS CARACTERÍSTICOS \\
\hline Informativo & AT, reinterpretación \\
\hline Entonativo & Pausa \\
\hline Distribución & Final de oración o enunciado \\
\hline $\begin{array}{l}\text { Relación } \\
\text { sintáctica }\end{array}$ & $\begin{array}{l}\text { Nuevo movimiento enunciativo. } \\
\text { Independencia sintáctica con respecto al verbo de la oración. }\end{array}$ \\
\hline $\begin{array}{l}\text { Función } \\
\text { discursiva }\end{array}$ & $\begin{array}{l}\text { - Compartida con MI: modalidad y enunciación. } \\
\text { - Específica: } \\
\text { a) Restricción } \rightarrow \text { contraargumentación } \\
\text { b) Progresión temática } \rightarrow \text { añadido informativo o digresión } \\
\text { c) Comentario } \rightarrow \text { evaluación modal }\end{array}$ \\
\hline $\begin{array}{l}\text { Manifestación } \\
\text { sintáctica }\end{array}$ & $\begin{array}{l}\text { Preposición }+\mathrm{sn} \\
\text { Relativos, } y, o+\text { oración }+ \text { (operadores argumentativos, } \\
\text { de reinterpretación, o conectores como por otra parte, } \\
\text { por lo demás) } \\
\text { Marcadores modales y enunciativos }\end{array}$ \\
\hline
\end{tabular}

TABLA 5: Ámbitos y rasgos característicos del MD

${ }^{29}$ Los elementos situados en el paréntesis son de presencia opcional. 
El MD es un mecanismo de sintaxis discursiva, supraoracional, que se vale de estructuras sintácticas como las oraciones de relativo, las copulativas, o las modificaciones a través de sintagmas nominales, para conseguir estos efectos.

\section{REFERENCIAS BIBLIOGRÁFICAS}

Alarcos, E. (1973): «Aditamento, adverbio y cuestiones conexas», en Alarcos, E., Estudios de gramática funcional del español, Madrid, Gredos, pp. 219-253.

Ashby, W. J. (1988): «The syntax, pragmatics, and sociolinguistics of left- and right-dislocations in French», Lingua 75, pp. 203-229.

Asher, N y LASCARIdes, A. (2003): Logics of conversation, Cambridge, Cambridge University Press.

Asher, N. y VIEU, L. (2005): «Subordinating and coordinating discourse relations», Lingua 115, pp. 591-610.

AvERINTSEVA-KLISCH, M. (2008): «German right dislocation and afterthought in discourse», en Benz, A. y Kühnlein, P. (eds), Constraints in discourse, Ámsterdam-Filadelfia, J. Benjamins, pp. 225-247.

Bally, C. (1965): Linguistique générale et linguistique française, 4ª ed., Berna, Francke.

Berruto. G. (1985): «'Dislocazioni a sinistra' e 'grammatica' dell'italiano parlato", en Franchi De Bellis, A. y Savoia, L. M. (eds.), Sintassi e morfologia della lingua italiana d'uso. Teorie e applicazioni descrittive, Roma, Bulzoni, pp. 59-82.

- (1986): «La dislocazione a destra in italiano», en Stammerjohan, H. (ed), Tema-rema in italiano, Tubinga, Gunter Narr Verlag, pp. 55-69.

BRInTON, L. J. (2008): The comment clause in English, Cambridge, Cambridge University Press.

BRIZ, A. y EsTellés, M. (2010): «On the relationship between attenuation, discourse particles and position», en Kaltenböck, G. et al. (eds.), New approaches to hedging, Bingley, Emerald, pp. 289-304.

BRUnetTI, L. (2009): «On links and tails in Italian», Lingua 119, pp. 756-781.

CAFFI, C. (1999): «On mitigation», Journal of Pragmatics 3, pp. 881-909.

- (2007): Mitigation, Oxford, Elsevier.

Dehé, N. y Kavalova, Y. (eds.) (2007): Parentheticals, Ámsterdam-Filadelfia, J. Benjamins.

DEPRAETERE, I. (1996): «Foregrounding in English relative clauses», Linguistics 34, pp. 699-731.

DIK, S. C. (1997a): The theory of functional grammar, $2^{\mathrm{a}}$ ed., vol. 1, Berlín, Mouton de Gruyter.

- (1997b): The theory of functional grammar, $2^{\underline{a}}$ ed., vol. 2, Berlín, Mouton de Gruyter.

Doetjes, J. et al. (2002): «The prosody of left detached constituents in French», Speech prosody, <http://lpl.univ-aix.fr/sp2002/pdf/doetjes-etal>.

Ducrot, O. (1995): «Les modificateurs déréalisants», Journal of Pragmatics 24, pp. $145-165$. 
ERLBABH M. S. (1987): «A uniform pause and error strategy for native and nonnative speakers», en Tomlin, R. S. (ed.), Coherence and grounding in discourse, vol. 11, Ámsterdam, J. Benjamins, P. C., pp. 109-130.

FERnÁNDEZ Fernández, A. (1993): La función incidental en español, Oviedo, Universidad de Oviedo.

FRANCESCONI, A. (2005): «La dislocación en la sintaxis italiana y española. Aspectos textuales y traductivos», Actas del XXIII AISPI (Associazione ispanisti italiani), pp. 202-222.

Fraser, B. (1975): «Hedged performatives», en Cole, P. y Morgan, J. L. (eds.), Syntax and semantics, vol. 3, Nueva York, Academic Press, pp. 187-210.

- (2010): «Pragmatic competence: the case of hedging», en Kaltenböck, G. et al. (eds.), New approaches to hedging, Bingley, Emerald, pp.15-34.

Fuentes RodríGuez, C. (1987a): «El adverbio de frase», RESLA 3, pp. 55-74.

- (1987b): Enlaces extraoracionales, Sevilla, Alfar.

- (1991): «Algunas reflexiones sobre el concepto de modalidad», RESLA 7, pp. 93-108.

— (1993): «Conectores pragmáticos», en Alcaide, E. y otros (eds), Estudios lingüisticos en torno a la palabra, Sevilla, Universidad de Sevilla, pp. 71-104.

- (1996): La sintaxis de los relacionantes supraoracionales, Madrid, Arco/Libros.

- (1998): «Estructuras parentéticas», LEA 20/2, pp. 137-174.

- (2000): Lingüistica pragmática y análisis del discurso, Madrid, Arco/Libros.

- (2001): «Los marcadores del discurso, ¿una categoría gramatical?», en Méndez, E. et al. (eds.), Indagaciones sobre la lengua. Estudios de filología y lingüística españolas en memoria de Emilio Alarcos, Sevilla, Universidad de Sevilla, pp. 323-348.

- (2005a): «Hacia una sintaxis del enunciado», LEA 17/1, pp. 33-61.

- (2005b): «Operadores de preferencia», ELUA 19, pp. 107-136.

- (2006): «Eso si y la reinterpretación enunciativa», Oralia, 9, pp. 305-318.

- (2007): La sintaxis del enunciado: los complementos periféricos, Madrid, Arco/ Libros.

- (2008): «La aproximación enunciativa», LEA 30/2, pp. 223-258.

- (2009): Diccionario de conectores y operadores del español, Madrid, Arco/Libros.

- (2012a): «Las oraciones de comentario en español», Actas del XXVI CILFR, Berlín, Walter de Gruyter, e.p.

- (2012b): «Marcadores del discurso y función comentario», Romanische Forschungen 124/4, pp. 449-470.

FuENTES, C. y AlCAIDE, E. (1996): La expresión de la modalidad en el habla urbana de Sevilla, Excmo. Ayuntamiento de Sevilla.

- (2002): Mecanismos lingüisticos de la persuasión, Madrid, Arco/Libros.

GALMÉs, A. (1955): «Influencias sintácticas y estilísticas del árabe en la prosa medieval castellana», BRAE 35, pp. 213- 275 y 36, pp. 65-131; 255-307.

García Negroni, M. M. (2003): Gradualité et réinterprétation, Paris, L'Harmattan.

GIVón, T. (1987): «Beyond foreground and background», en Tomlin, R. S. (ed.), pp. $175-188$.

GeLUYKENs, R. (1987): «Tails (right-dislocation) as a repair mechanism in English conversation», en Nuyts, J. y De Schutter, G. (eds), Getting one's words into line, Dordrecht, Foris, pp. 119-129. 
GreEnbaum, S. (1969): Studies in English adverbial usage, Londres, Longman.

GuTIÉRREZ ORDÓÑEZ, S. (1997): «La determinación de los niveles oracionales», en La oración y sus funciones, Madrid, Arco/Libros, pp. 368-426.

Hidalgo, R. (2003): La tematización en español, Madrid, Gredos.

KALtenBöck, G. et al. (2010) (eds.): New approaches to hedging, Bingley, Emerald. KovacCI, O. (1992): El comentario gramatical, Madrid, Arco/Libros.

- (1999): «El adverbio», en Bosque, I. y Demonte, V. (eds.), Gramática descriptiva de la lengua española, Madrid, Espasa, pp. 705-786.

LAKOFF, G. (1972): «Hedges: a study in meaning criteria and the logic of fuzzy concepts», Papers from the eight regional meeting of the Chicago linguistic society, Chicago, Chicago Lingustics Society, pp. 183-228.

LAMBRECHT, K. (1981): Topic, antitopic and verb agreement in non-standard French, Ámsterdam, Benjamins.

LAPESA, R. (1975): «Sintaxis histórica del adjetivo calificativo no atributivo», en Homenaje al instituto de filología y literaturas hispánicas Doctor Amado Alonso en su cincuentenario (1923-1973), Buenos Aires, pp. 171-199. Recogido en Lapesa, R. (2000): Estudios de morfosintaxis histórica del español, vol. 1, edición de Cano Aguilar, R. y Echenique Elizondo, M. ${ }^{-}$T., Madrid, Gredos, pp. 235-271.

LARSSON, E. (1979): «La dislocation en français: étude de syntaxe générative», Études Romanes de Lund 28.

Martínez, J. A. (1994): «La función incidental y su conexión con otras construcciones del español», en Cuestiones marginadas de gramática española, Madrid, Istmo, pp. 225-283.

Martín Zorraquino, M. A. y Portolés Lázaro, J. (1999): «Los marcadores del discurso», en Bosque, I. y Demonte, V. (eds.), Gramática descriptiva de la lengua española, Madrid, Espasa, pp. 4051-4213.

NøLKe, H. (1994): Linguistique modulaire: de la forme au sens, Lovaina-París, Peeters.

Östman, J.-O. (1981): You know: a discourse functional view, Ámsterdam, J. Benjamins.

Padilla, X. (2001): El orden de palabras en el español coloquial, Valencia, Publicaciones Universitat de València.

Pérez Bello, G. (1998): «Uso de las dislocaciones a la derecha y a la izquierda en castellano e italiano», Interlingüistica 9, pp. 253-259.

PrINCE, E. F. et al. (1982): «On hedging in physician-physician discourse», en Di Pietro, R. J. (ed.), Linguistics and the professions. Proceedings of the second annual Delaware symposium on language studies, Norwood, Ablex, pp. 83-97.

QuiRk, R. y otros (1972): A comprehensive grammar of the English language, Londres, Longman.

RAE (2009): Nueva gramática de la lengua española, Madrid, Espasa.

RoDMAN, R. (1975): «Right dislocation», Paper presented at the south-eastern conference on linguistics, Atlanta, <http://www.eric.ed.gov/PDFS/ED117974.pdf > .

SAmek-Lodovici, V. (2006): «When right dislocation meets the left-periphery. A unified analysis of Italian non-final focus», Lingua 116, pp. 836-873. 
Schelfhout, C.; Coppen, P. A. y Östdijk, N. (2004): «Finite comment clauses in Dutch: a corpus-based approach", Journal of Germanic Linguistics 16.4, pp. 331-349.

SCHNEIDER, S. (2007): Reduced parenthetical clauses as mitigators, Ámsterdam-Filadelfia, J. Benjamins.

Stenström, A. B. (1995): «Some remarks on comment clauses», en Aarts, B. y Meyer, C. F. (eds), The verb in contemporary English, Cambridge, Cambridge University Press, pp. 290-302.

TALMY, L. (1978): «Figure and ground in complex sentences», en Greenberg, J. (ed.), Universals of human language, vol. 4: Syntax, Stanford University Press, pp. $625-649$.

ThOMPSON, S. (1987): «Subordination and narrative event structure», en Tomlin, R. S. (ed), pp. 435-454.

TomLin (ed.) (1987): Coherence and grounding in discourse, vol. 11, Ámsterdam, J. Benjamins, P. C.

VAllduví, E., (1994): «Detachment in Catalan and information packaging», Journal of Pragmatics 22, pp. 573-601.

VIEU, L. y PrÉVOT, L. (2004): «Background in SDRT», Workshop SDRT, TALN-04, 22/04/2004, <ftp://ftp.irit.fr/IRIT/LILAC/PV-TALN04.pdf $>$.

VILLALbA, X. (2011): «A quantitative comparative study of right-dislocation in Catalan and Spanish», Journal of Pragmatics 43, pp. 1946-1961.

VION, M. (1992): «The role of intonation in processing left and right dislocations in French», Journal of Experimental Child Psychology 53/1, pp. 45-71.

ZAMORA, P. (2002): «Dislocazioni a destra e a sinistra nell'italiano e nello spagnolo colloquiale parlato: frequenza d'uso e parametri linguistici», Studi Italiani di Linguistica Teorica e Applicata, 21/3, pp. 447-470.

ZIv, Y. (2002): «This, I believe, is a processing instruction: Discourse linking via parenthetical», en Falk, Y. N. (ed.), Proceedings of Israel association for theoretical linguistics 18, Bar Ilan University, <http://micro5.msc.huji.ac.il/ -english/IATL/19/Ziv.pdf>. 
